\title{
In vitro evaluation of degradable electrospun polylactic acid/bioactive calcium phosphate ormoglass scaffolds
}

\author{
Anna Majchrowicz ${ }^{1}$ - A. Roguska ${ }^{2}$ - A. Krawczyńska ${ }^{1} \cdot$ M. Lewandowska ${ }^{1} \cdot$ J. Martí-Muñoz ${ }^{3,4,5} \cdot$ E. Engel $^{3}$. \\ O. Castano $3,4,6,7$
}

Received: 4 March 2020 / Revised: 8 March 2020 / Accepted: 7 April 2020 / Published online: 24 April 2020

(c) The Author(s) 2020

\begin{abstract}
Nowadays, the main limitation for clinical application of scaffolds is considered to be an insufficient vascularization of the implanted platforms and healing tissues. In our studies, we proposed a novel PLA-based hybrid platform with aligned and random fibrous internal structure and incorporated calcium phosphate $(\mathrm{CaP})$ ormoglass nanoparticles $(0,10,20$ and $30 \mathrm{wt} \%)$ as an off-the-shelf method for obtaining scaffolds with pro-angiogenic properties. Complex morphological and physicochemical evaluation of PLA-CaP ormoglass composites was performed before and after in vitro degradation test in SBF solution to assess their biological potential. The degradation process of PLA-CaP ormoglass composites was accompanied by numerous CaP-based precipitations with extended topography and cauliflower-like shape which may enhance bonding of the material with the bone tissue and accelerate the regenerative process. Random fiber orientation was preferable for CaP compounds deposition upon in vitro degradation. CaP compounds precipitated firstly for randomly oriented composite nonwovens with 20 and $30 \mathrm{wt} \%$ addition of ormoglass. Moreover, the preliminary bioactivity test has shown that BSA adsorbed to PLA-CaP ormoglass composites (both aligned and randomly oriented) with 20 and $30 \mathrm{wt} \%$ of ormoglass nanoparticles which was not observed for pure PLA scaffolds.
\end{abstract}

Keywords Composites $\cdot$ PLA $\cdot$ Calcium phosphate ormoglass $\cdot$ Electrospinning $\cdot$ Degradation

Anna Majchrowicz

anna.j.majchrowicz@gmail.com

1 Faculty of Materials Science and Engineering, Warsaw University of Technology (WUT), Wołoska 141, 02-507 Warsaw, Poland

2 Institute of Physical Chemistry, Polish Academy of Sciences, Warsaw, Poland

3 Biomaterials for Regenerative Therapies, Institute for Bioengineering of Catalonia (IBEC), The Barcelona Institute of Science and Technology (BIST), Barcelona, Spain

4 CIBER en Bioingeniería, Biomateriales y Nanomedicina, CIBER-BBN, Zaragoza, Spain

5 Materials Sciences and Metallurgy, Universitat Politècnica de Catalunya (UPC), Barcelona, Spain

6 Electronics and Biomedical Engineering, Universitat de Barcelona (UB), Barcelona, Spain

7 Institute of Nanoscience and Nanotechnology, University of Barcelona (UB), 08028 Barcelona, Spain

\section{Introduction}

Bone tissue is based on fibrous structures which are organized hierarchically. Therefore, nanofiber biomaterials are currently under deep investigation in the field of bone tissue regeneration. It has been shown that scaffolds possessing nanofibrous structure have beneficial impact on cellular responsiveness as they exhibit similarity in physical architecture to native extracellular matrix (ECM) [1-3]. Scaffolds obtained via electrospinning mimic bone ECM structure very trustworthy. Hence, they are widely investigated in the field of bone tissue engineering. Due to their easy formability and degradability, thermoplastic aliphatic polyester is commonly used to fabricate scaffolds. However, their mechanical properties as well as bioactivity and cell signaling are often insufficient. Thus, composite materials are now widely investigated to be commonly adapted in bone regeneration applications. Among them, combination of polylactic acid (PLA) as a polymer matrix and soluble calcium phosphate $(\mathrm{CaP})$ glass-ceramics in form of nanoparticles as a reinforcement seems to be very promising candidate 
[4-6]. PLA is one of the most commonly used materials for biomedical applications due to its desirable properties such as biodegradability, good compatibility and low toxicity [7]. Nowadays, PLA can be obtained from renewable resources at relatively low costs, requires low energy consumption during production and can be easily thermally processed compared to other polymers [8]. It has been approved in different applications by the Food and Drug Administration (FDA) and has been extensively studied and used in novel scaffolds for tissue repair. Besides, product of PLA degradation-lactate-has been reported to show an angiogenic effect by supporting expression of vascular endothelial growth factor (VEGF) [9].

Due to its biological potential, PLA is often used as the main component of composites for biomedical applications. In order to increase its mechanical strength as well as bioactivity, different types of ceramic components such as bioactive glasses are commonly used additives. Bioactive glasses have been extensively investigated in recent years in various fields of study due to their ability to promote gene expression regulating osteogenesis and angiogenesis [10]. Gritsch et al. provided recently an overview on strategies to improve tissue-material interface for polylactidebased materials, concerning among them different types of bioactive glasses [11]. Mao et al. reported previously that incorporation of bioactive glass to PLA-based composite significantly improved its bioactivity. They claimed that degradation rate of such composite scaffolds could be easily regulated by adjusting the bioactive glass content to match the regeneration process of new bone [12]. There are evidences that PLA-bioactive glass composites can promote hydroxyapatite formation upon in vitro degradation [13, 14]. Bellucci et al. claimed that bioactive glass can release VEGF upon in vitro degradation which suggests its angiogenic potential [15].

Apart from bioactive glass, calcium phosphate organically modified glasses ( $\mathrm{CaP}$ ormoglasses) can be used to increase the biological potential of PLA-based composites. It has been demonstrated that $\mathrm{CaP}$ ormoglasses in the system $\mathrm{P}_{2} \mathrm{O}_{5}-\mathrm{CaO}-\mathrm{Na}_{2} \mathrm{O}-\mathrm{TiO}_{2}$ possess interesting mechanical, bioactive and degradation properties [16-18]. They degrade totally in body fluids within time ranging from few days to several months, releasing in that period $\mathrm{Ca}^{2+}$ ions. The most promising feature is its ability to trigger the angiogenic process and promote the formation of vessels, as has been studied both in vitro [19] and in vivo [20]. Recently, NavarroRequena et al. reported as well on wound healing-promoting effects of such $\mathrm{CaP}$ ormoglasses that can stimulate wound healing responses of dermal fibroblasts [21].

In this paper, nanofibrous composite material made of PLA matrix and nanoparticles of CaP ormoglass fabricated by electrospinning was investigated as an envelope which mimics the periosteum to maintain a filling for bone regeneration. The key issues here are to provide a high bioactive nonwoven electrospun scaffold to allow the envelopment of a bone filler. CaP bioresorbable ormoglasses, which have controllable solubility and the ability to trigger the angiogenic process, were incorporated into polymeric fibers to obtain a hybrid material suitable for bone regeneration applications. Electrospun mats were fabricated having two types of fiber orientation: aligned (a) and randomly oriented (r). Different concentrations of ormoglass filler $(0,10,20$ and $30 \mathrm{wt} \%)$ were investigated to determine its effect on biological properties. Complex morphological and physicochemical evaluation of composite scaffolds as well as in vitro degradation test in simulated body fluid (SBF) solution was made in order to obtain overall material characteristic and assess their potential angiogenic properties. The preliminary bioactivity test was also conducted with simple protein adsorption test using bovine serum albumin (BSA) as a model protein.

\section{Materials and methods}

\subsection{Sample preparation}

Poly-1/dl lactic acid 70/30 (PLA70/30 Corbion PLDL 7038, inherent viscosity midpoint $3.8 \mathrm{dl} \mathrm{g}^{-1}$, molecular mass $\approx$ $850,000 \mathrm{Da}$, Gorinchem, The Netherlands) was used as the composite matrix. Ormoglass nanoparticles with a composition of 59:30:8:3 $\mathrm{P} / \mathrm{Ca} / \mathrm{Na} / \mathrm{Ti}$ molar ratio were prepared by controlled sol-gel hydrolysis and added as a filler to the composites. The ormoglass production method consisting of mixing different alkoxide precursors of $\mathrm{Ca}, \mathrm{Na}$, $\mathrm{Ti}$ and $\mathrm{P}$ in an Ar-controlled atmosphere was reported previously [22]. The mixes were hydrolyzed in basic aqueous media, dispersed and stirred in anhydrous 1,4-dioxane (SigmaAldrich $99.8 \%$ ) for 4 days at $70{ }^{\circ} \mathrm{C}$. They were then washed, collected by centrifugation and dried at $85^{\circ} \mathrm{C}$. Electrospinning slurries were prepared by ultrasonically dispersing ormoglass nanoparticles $(0,10,20$ and $30 \mathrm{wt} \%$ respect total weight of polymer plus particles) in a solution of PLA 70/30 $4 \mathrm{wt} \%$ in 2,2,2-trifluoroethanol (Panreac 99.8\%). Then, they were electrospun at $10 \mathrm{kV}$ with a $15-\mathrm{cm}$ tip-collector distance using a rotary (aligned nonwovens) or flat (randomly oriented nonwovens) collector working at $1000 \mathrm{rpm}$. The obtained electrospun scaffolds with different concentrations of CaP ormoglass, i.e., 0, 10, 20 and $30 \mathrm{wt} \%$, are further referred to as PLA, PLA10GS, PLA20GS and PLA30GS, respectively.

\subsection{In vitro degradation}

In vitro degradation studies were carried out using SBF prepared following the standard procedure described by Kokubo 
et al. [23]. Briefly, $\mathrm{NaCl}(8.035 \mathrm{~g}), \mathrm{NaHCO}_{3}(0.355 \mathrm{~g}), \mathrm{KCl}$ $(0.225 \mathrm{~g}), \mathrm{K}_{2} \mathrm{HPO}_{4} \cdot 3 \mathrm{H}_{2} \mathrm{O}(0.231 \mathrm{~g}), \mathrm{MgCl} \cdot 6 \mathrm{H}_{2} \mathrm{O}(0.311 \mathrm{~g})$, $1 \mathrm{M} \mathrm{HCl}(39 \mathrm{ml}), \mathrm{CaCl}_{2}(0.292 \mathrm{~g}), \mathrm{Na}_{2} \mathrm{SO}_{4}(0.072 \mathrm{~g})$ and Tris $(6.118 \mathrm{~g})$ were dissolved individually in deionized water in order to avoid precipitation and maintain the $\mathrm{pH}$ in the range. Final pH was 7.4 at $37^{\circ} \mathrm{C}$. Electrospun nonwovens for the biomineralization study were cut into rectangular pieces with dimensions $8 \times 15 \mathrm{~mm}$ (thickness of each nonwoven was in the range of $200-250 \mu \mathrm{m}$ ) and immersed separately in $12 \mathrm{ml}$ of medium at $37{ }^{\circ} \mathrm{C}$ for 21 days. The $\mathrm{SBF}$ solution was refreshed every 3 days to ensure sufficient ions concentration. At predetermined control points (1, 7, 14 and 21 days), samples were removed from the SBF, rinsed gently with deionized water and dried.

\subsection{SEM/STEM observation and EDS measurements}

The morphology of electrospun nonwovens before and during controlled degradation in SBF solution was characterized using scanning electron microscope (SEM) Hitachi SU8000 operating at $5 \mathrm{kV}$ and scanning transmission electron microscope (STEM) Hitachi S5500 with an applied voltage of $30 \mathrm{kV}$. In order to improve surface conductance, samples were sputtered for $120 \mathrm{~s}$ with gold at voltage of $2 \mathrm{kV}$ and current of $5 \mathrm{~mA}$. Fibers diameter was measured with ImageJ software, and at least 50 measures were done for each sample. Elemental composition of the surface was characterized by energy-dispersive X-ray (EDS) analysis coupled with SEM Hitachi SU8000. To obtain chemical distribution maps, voltage of $15 \mathrm{kV}$ was applied.

\subsection{FTIR measurements}

The changes in chemistry after incubation in SBF were examined using Fourier transform infrared spectroscopy (FTIR, Thermo Electron Nicolet 8700, Thermo Scientific). FTIR spectra were collected in the range from 4000 to $400 \mathrm{~cm}^{-1}$ with resolution at $4 \mathrm{~cm}^{-1}$.

\subsection{XPS measurements}

Chemical state and composition of each element on the surface of nonwoven materials before and after degradation in SBF were determined using a Microlab 350 spectrometer (Thermo Electron Corporation) with X-ray photoelectron spectroscopy (XPS) function. XPS spectrums were excited using $\mathrm{Al} \mathrm{K} \alpha(h v=1486.6 \mathrm{eV})$ radiation as a source. Survey and high-resolution spectrum were recorded using 150 and $40 \mathrm{eV}$ pass energy. A linear or Shirley background subtraction was made to obtain XPS signal intensity. The peaks were fitted using an asymmetric Gaussian/Lorentzian mixed function. The measured binding energies were corrected referring to energy of $\mathrm{C} 1 \mathrm{~s}$ at $285.0 \mathrm{eV}$. The spectra were developed using Avantage software (version 5.41).

\subsection{Protein adsorption}

For initial evaluation of the biocompatibility of nonwovens fibers, protein adsorption test was performed using BSA (Sigma-Aldrich, 99.8\%) as a "model" protein. BSA has been chosen due to its chemical inertness to many biochemical reactions as well as low cost. BSA was dissolved $\left(1 \mathrm{~g} \mathrm{ml}^{-1}\right)$ in phosphate-buffered saline ( $\mathrm{pH} 7.4$ ), and $100 \mu \mathrm{l}$ of the solution was added to each sample. All tested materials were incubated at $37{ }^{\circ} \mathrm{C}$ for $20 \mathrm{~min}$ and then subjected to surface chemical composition analysis using FTIR spectroscopy.

\section{Results}

\subsection{Pre-degradation}

\subsubsection{SEM/STEM observation}

PLA-CaP ormoglass composites obtained via electrospinning method possess a nonwoven fibrous structure as shown in Fig. 1. For aligned nonwovens, pure PLA scaffold exhibits the minimum average value of fiber diameter, i.e., $287 \pm 69 \mathrm{~nm}$, whereas PLA-CaP ormoglass composites consist of fibers with the average diameter of approximately $400 \mathrm{~nm}$. For randomly oriented nonwovens, the average fiber diameter values are much higher, i.e., $902 \pm 232$, $845 \pm 68,955 \pm 245$ and $584 \pm 103 \mathrm{~nm}$ for rPLA, rPLA10GS, rPLA20GS and rPLA30GS, respectively. The differences in obtained values of fiber diameter can be attributed to specific fabrication method.

As shown in Fig. 1, pure PLA fibers possess homogeneous structure without visible beads or other significant defects with uniform thickness throughout their length. For aligned nonwovens, high linear orientation of fibers is observed. In case of PLA-CaP ormoglass composites, fibers possess homogeneous structure and are uniform in their thickness as well. Round particles of ormoglass can be detected in the scaffold structure in small amount. STEM images reveal the $\mathrm{CaP}$ ormoglass particles incorporated into fibers and protruded from them. They possess miscellaneous shapes and sizes ranging from approximately 150 to $700 \mathrm{~nm}$. Smaller particles seem to have more round shape and be enclosed inside the polymer fiber, whereas the bigger particles stacked out from the fibers and be rather polyhedron shape. STEM images for pure PLA fibers demonstrate smooth structure without any internal elements. 


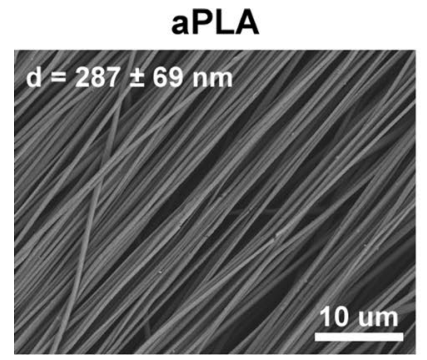

rPLA

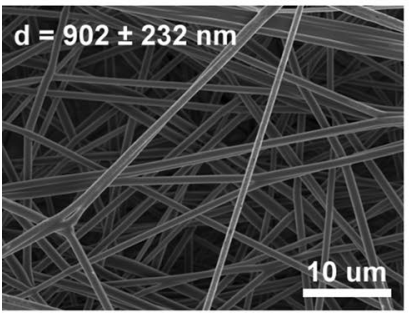

aPLA10GS

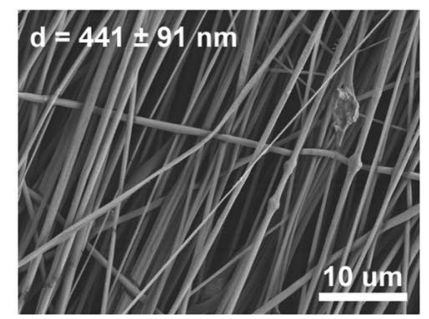

rPLA10GS

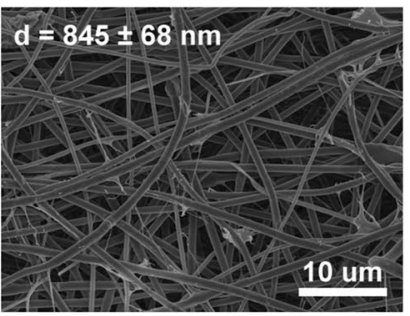

aPLA20GS

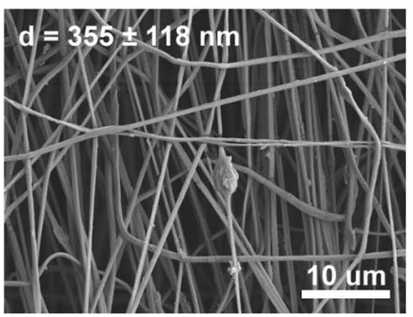

rPLA20GS

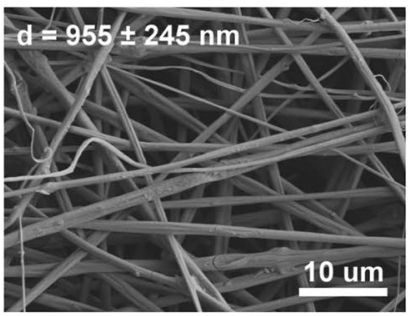

aPLA30GS

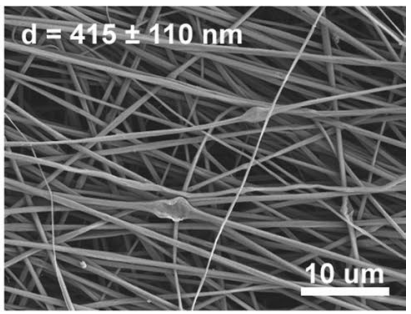

rPLA30GS

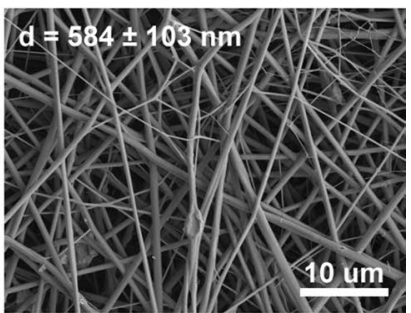

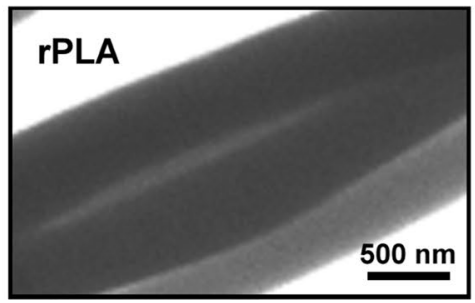

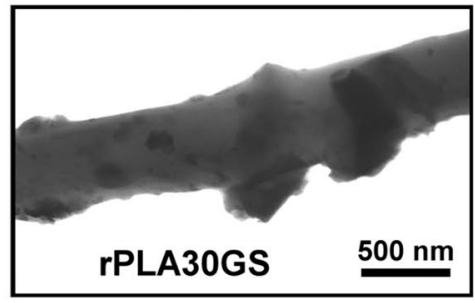

Fig. 1 Morphology of aligned and randomly oriented PLA-CaP ormoglass composites at initial state

\subsubsection{FTIR measurements}

Figure 2 presents results obtained for FTIR examination of chemical composition of PLA-CaP ormoglass composites and pure PLA nonwovens. Both aligned and randomly oriented nonwovens were examined. All spectra show several main regions corresponding to the polymer matrix: $\mathrm{C}=\mathrm{O}$ stretching at $1750-1745 \mathrm{~cm}^{-1}, \mathrm{C}-\mathrm{H}$ bending at $1500-1400 \mathrm{~cm}^{-1}$ and $\mathrm{C}-\mathrm{O}$ stretching at $1100-1000 \mathrm{~cm}^{-1}$ [24]. For PLA-CaP ormoglass composites, additional signals can be distinguished due to the presence of phosphate complexes: P-O-P asymmetric stretching at $910 \mathrm{~cm}^{-1}[25$,
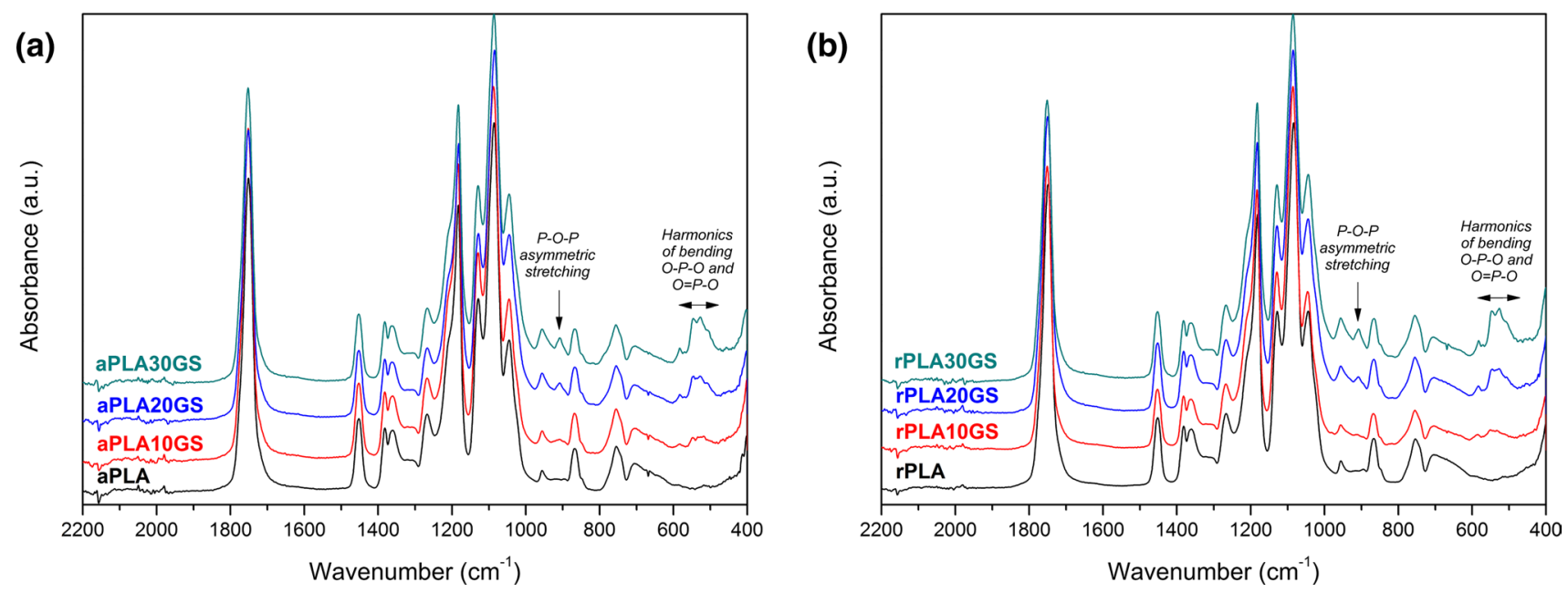

Fig. 2 FTIR results for $\mathbf{a}$ aligned and $\mathbf{b}$ randomly oriented PLA-CaP ormoglass composites at initial state 
26] and region between 480 and $600 \mathrm{~cm}^{-1}$ relating to the bending vibrations $\mathrm{O}-\mathrm{P}-\mathrm{O}$ and $\mathrm{O}=\mathrm{P}-\mathrm{O}$ in phosphate groups $[25,27]$. The intensity of those peaks increases for higher content of ormoglass filler which suggests they are related to the vibration of $\mathrm{PO}_{4}$ phosphate groups in $\mathrm{CaP}$ ormoglass as shown in our previous work [28]. No significant differences can be observed between aligned and randomly oriented nonwovens.

\subsection{Post-degradation}

\subsubsection{SEM observation}

Figures 3 and 4 present results of SEM observation of PLA-CaP ormoglass composites after incubation in SBF solution after 1, 7, 14 and 21 days of the test for aligned and random orientation, respectively. Significant changes in the morphology of reference pure PLA sample and PLA-CaP ormoglass composites upon incubation can be observed. Numerous perforation and traversal cracks can be found on the fibers as well as thin film of melted polymer which is a result of hydrolytic degradation of the composite matrix. The cracking and dissolving of the fibers lead to partial loss of initial microstructure and linearity of aligned nonwovens. The degradation process is accompanied by precipitation from SBF of characteristic particles with developed surface area resembling cauliflower-like shape (marked by white arrows). These particles were recognized by EDS analysis as CaP-based precipitates as shown in Fig. 4.

Comparing aligned and randomly oriented PLA-CaP ormoglass composites, random fiber orientation seems to be preferable for $\mathrm{CaP}$ compounds deposition upon in vitro degradation. $\mathrm{CaP}$ compounds precipitate firstly for rPLA20GS and rPLA30GS samples after 7 days of incubation. Longer incubation in SBF (14 and 21 days) results in further mineralization of all randomly oriented PLA-CaP ormoglass composites. Mineralization process is not so clearly observed for aligned nonwovens. Small amounts of $\mathrm{CaP}$ precipitate for aPLA20GS and aPLA30GS composites after 21 days of incubation.

It should be mentioned that no $\mathrm{CaP}$ compounds precipitate in case of pure PLA nonwovens (both aligned and randomly oriented). The most pronounced mineralization process was observed for rPLA20GS composite, and therefore, the degradation process will be further discussed on the example of that composite.

\subsubsection{FTIR and XPS measurements}

Figure 5 presents FTIR results of chemical analysis of rPLA20GS after incubation in SBF. There are a few
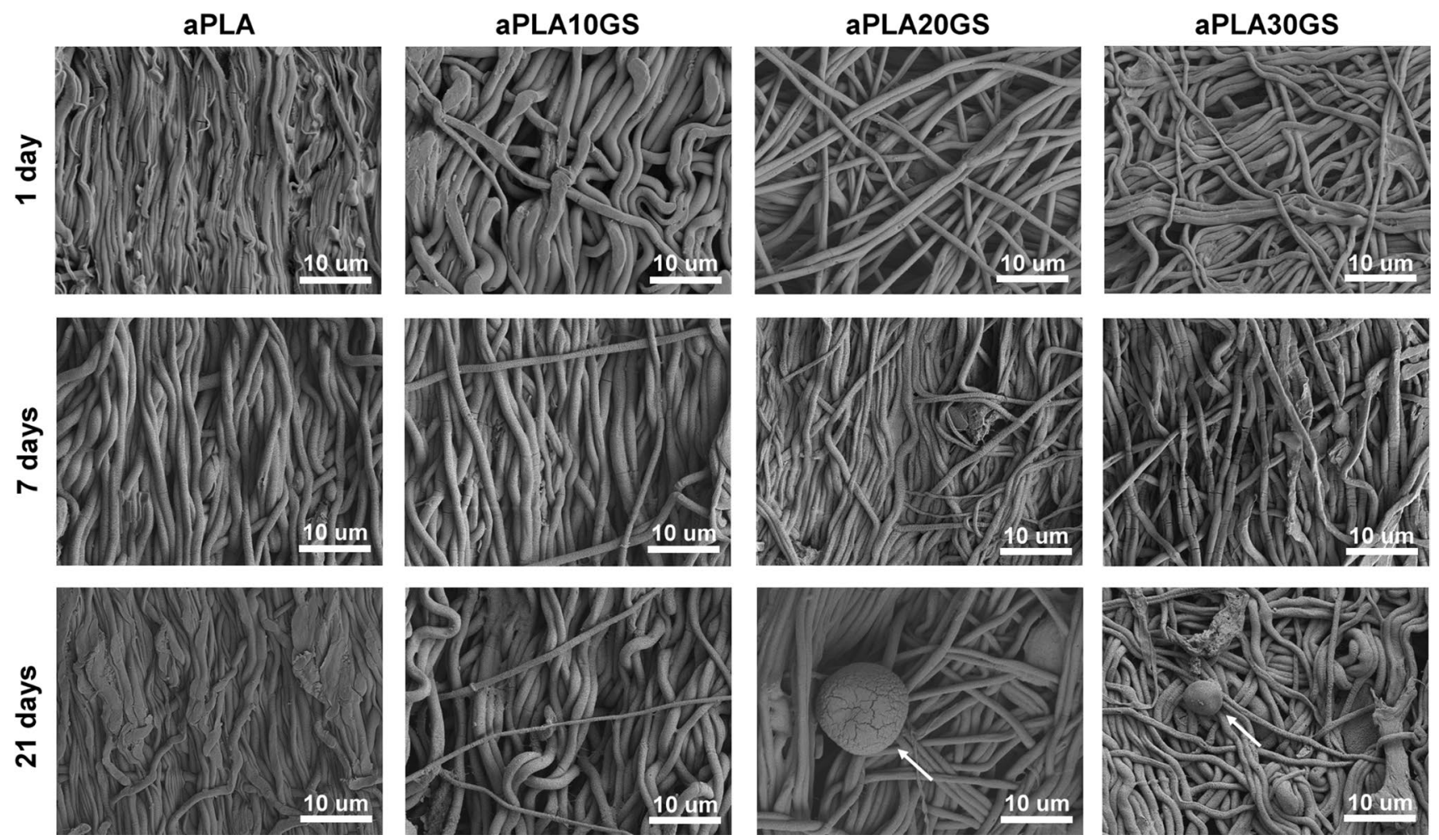

Fig. 3 Morphology of aligned PLA-CaP ormoglass composites after incubation in SBF solution for 1, 7 and 21 days 

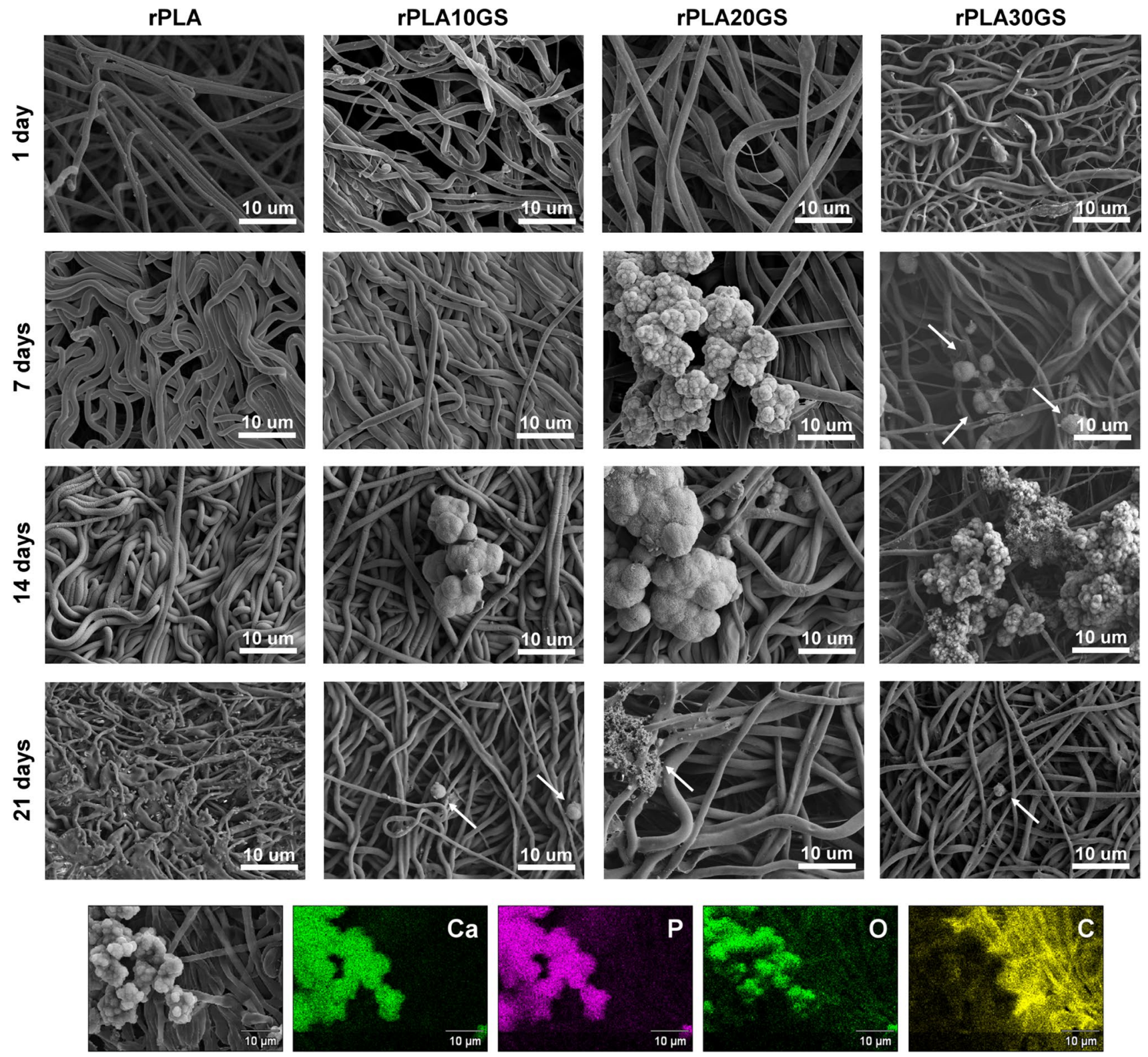

Fig. 4 Morphology of randomly oriented PLA-CaP ormoglass composites after incubation in SBF solution for 1, 7, 14 and 21 days and EDS analysis for rPLA20GS after 7 days of incubation

differences in the spectra compared to the initial state. All peaks related to the presence of $\mathrm{CaP}$ ormoglass, i.e., at $910 \mathrm{~cm}^{-1}$ as well as those in the region from 480 to $600 \mathrm{~cm}^{-1}$, have disappeared after 1 day of incubation. After 14 days of incubation, additional peaks were detected at 559 and $601 \mathrm{~cm}^{-1}$ which also represent $\mathrm{v}_{4} \mathrm{O}-\mathrm{P}-\mathrm{O}$ bending vibrations of $\mathrm{PO}_{4}$ groups in phosphates [29-32]. This result coincides with SEM observation, i.e., the most pronounced precipitation of $\mathrm{CaP}$ particles was observed after 14 days of incubation.

Table 1 presents the results of XPS investigation for rPLA20GS scaffolds before and after incubation in SBF.
Analysis of the results shows that content of calcium and phosphorus increases after incubation in SBF. It is also clear that $\mathrm{Ca} / \mathrm{P}$ ratio rises gradually with incubation time. This result coincides with SEM observation of cauliflower-like shape CaP-based particles precipitated at the surface of composite scaffolds (Fig. 4).

The significant reduction of $\mathrm{C}$ and $\mathrm{O}$ content at the expense of $\mathrm{Ca}$ and $\mathrm{P}$ can be clearly observed after 21 days of incubation. As shown in Fig. 6, it may result from the degradation of PLA matrix of scaffolds. Figure 6 shows the C1s XPS spectra of pure PLA scaffold before (Fig. 6a) and after (Fig. 6b) the degradation test in SBF solution 


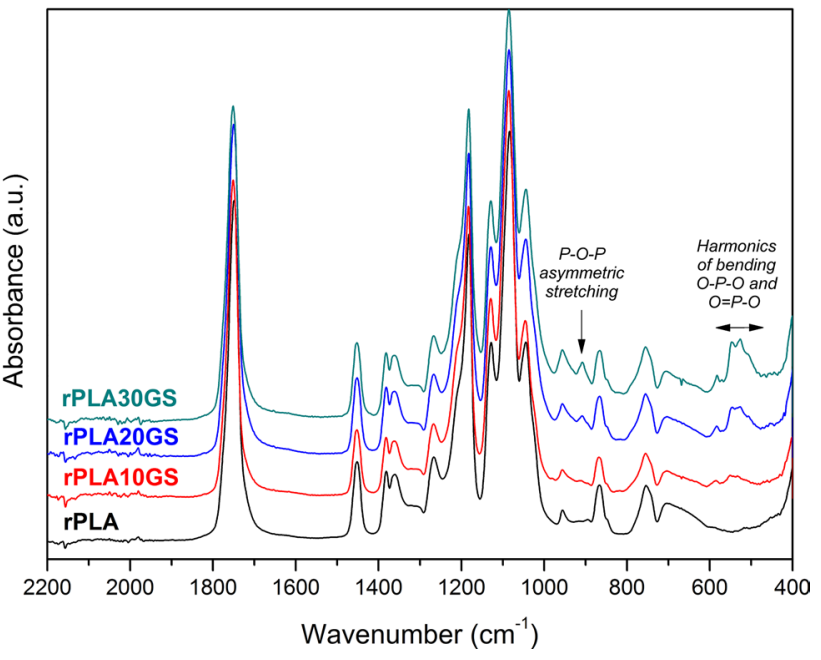

Fig. 5 FTIR results for rPLA20GS after incubation in SBF for 1, 7, 14 and 21 days

for 21 days. A new characteristic peak of C1s at $287.5 \mathrm{eV}$ after the degradation test can be distinguished. The new $\mathrm{C} 1$ s peak is related to the degradation products of PLA such as $\mathrm{C} 1 \mathrm{~s}(\mathrm{C}-\mathrm{O}$ and $\mathrm{O}-\mathrm{C}-\mathrm{O})$ bonding types. It results from the hydrolysis and degradation of the ester groups of the PLA main chain under incubation in SBF solution (aqueous solution).

\subsection{Protein adsorption}

The results of the preliminary test of biocompatibility (protein adsorption test using BSA) are presented in Fig. 7. There is a slight change in the spectra for aligned (Fig. 7a) and randomly oriented (Fig. 7b) PLA-CaP ormoglass composites with 20 and $30 \mathrm{wt} \%$ addition of ormoglass nanoparticles as compared to the initial state. Small peaks at $\sim 1655$ and $\sim 1540 \mathrm{~cm}^{-1}$ have appeared for these composites. The first peak corresponds mostly to the stretching vibrations of the $\mathrm{C}=\mathrm{O}$ groups and less to the $\mathrm{C}-\mathrm{N}$ groups present in amides I. The second lower peak at $\sim 1540 \mathrm{~cm}^{-1}$ correlates mainly with bending of $\mathrm{N}-\mathrm{H}$ group in amide II [33].

\section{Discussion}

In this paper, evaluation of structural and chemical changes of electrospun PLA-CaP ormoglass composites after in vitro simulated degradation in physiological conditions (SBF solution) was studied. The addition of ormoglass nanoparticles modified the degradation of PLA-CaP ormoglass
Table 1 Chemical composition (in at.\%) of rPLA20GS after incubation in SBF

\begin{tabular}{llllllllll}
\hline Incubation time & $\mathrm{C}$ & $\mathrm{O}$ & $\mathrm{Ca}$ & $\mathrm{P}$ & $\mathrm{Ti}$ & $\mathrm{Na}$ & $\mathrm{Mg}$ & $\mathrm{Cl}$ & $\mathrm{Ca} / \mathrm{P}$ \\
\hline Initial state & 70.0 & 27.5 & 0.5 & 1.5 & 0.2 & 0.3 & - & - & 0.33 \\
1 day & 68.6 & 27.4 & 1.1 & 1.7 & 0.3 & 0.1 & 0.1 & 0.7 & 0.65 \\
7 days & 68.0 & 28.8 & 0.9 & 1.2 & 0.3 & 0.1 & 0.1 & 0.6 & 0.75 \\
14 days & 68.2 & 28.2 & 0.8 & 1.4 & 0.4 & 0.1 & 0.1 & 0.8 & 0.57 \\
21 days & 62.7 & 30.3 & 3.0 & 3.3 & 0.3 & 0.1 & 0.1 & 0.2 & 0.91 \\
\hline
\end{tabular}
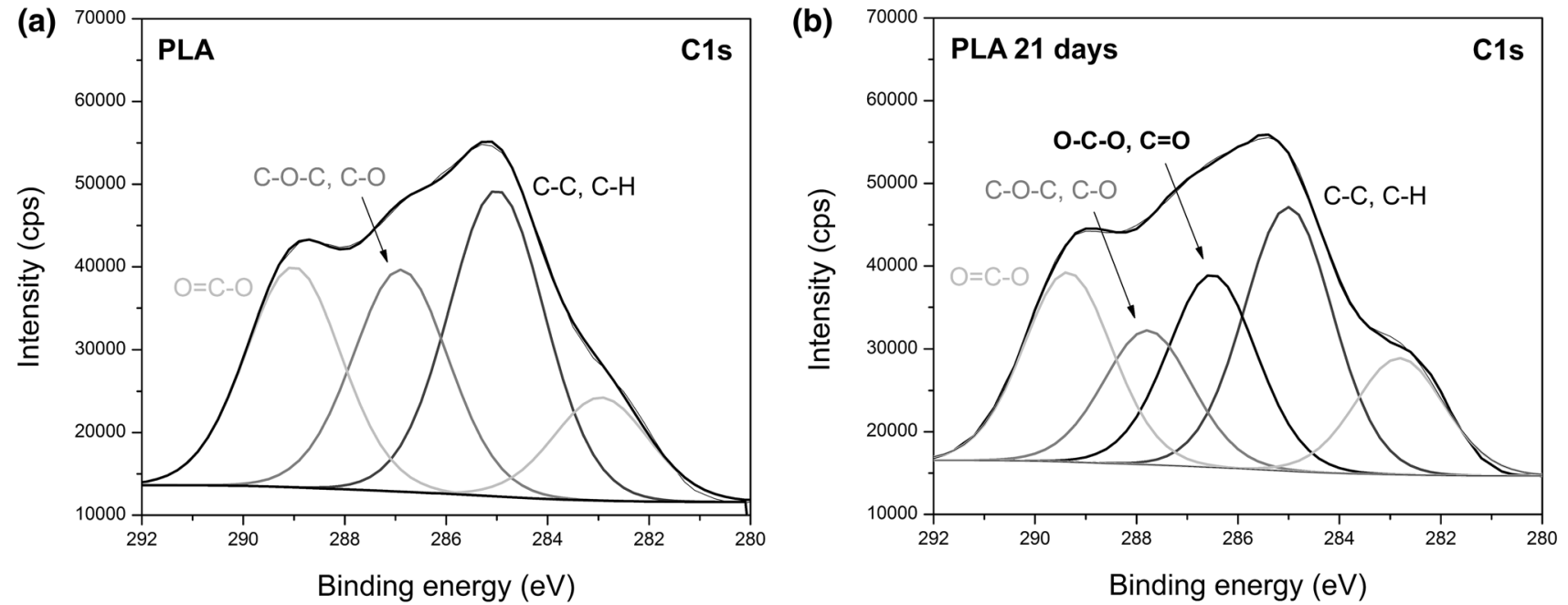

Fig. 6 XPS results for rPLA a before and $\mathbf{b}$ after incubation in SBF for 21 days 

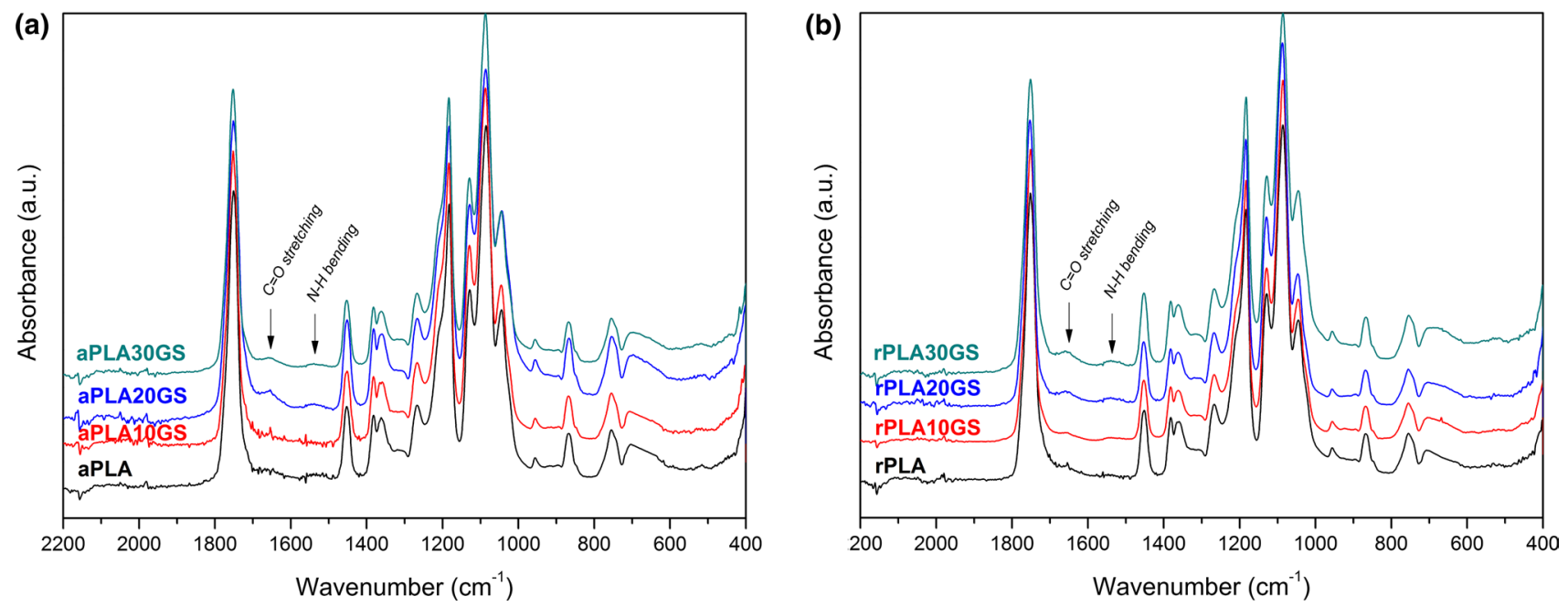

Fig. 7 FTIR results for a aligned and $\mathbf{b}$ randomly oriented PLA-CaP ormoglass composites after protein adsorption test using bovine serum albumin (BSA)

composites and caused differences in the morphology and chemical properties of material surface. Referring to the changes in the morphology after various periods of SBF incubation, the presence of $\mathrm{CaP}$ precipitations partly covering the nonwovens was observed only for PLA-CaP ormoglass composites (Figs. 3, 4). No CaP compounds formed in case of pure PLA nonwovens (both aligned and randomly oriented) which indicates that $\mathrm{CaP}$ ormoglass nanoparticles initiate and highly accelerate the precipitation process of $\mathrm{CaP}$ compounds. Besides, it should be noted that random fiber orientation strongly favored $\mathrm{CaP}$ formation. For randomly oriented scaffolds (rPLA20GS and rPLA30GS), CaP compounds precipitated after 7 days of incubation, whereas for aligned ones (aPLA20GS and aPLA30GS) only small $\mathrm{CaP}$ precipitates were observed after 21 days of incubation. The extended topography of detected $\mathrm{CaP}$ particles may improve the bioactivity and biological response of the electrospun PLA-CaP ormoglass composites. Developed surface area of those precipitations can promote bonding the material with the bone tissue accelerating the regeneration process of bone fracture.

The another important aspect of bone regeneration process in case of the investigated PLA-CaP ormoglass composites is the chemical composition of $\mathrm{CaP}$ precipitates formed during degradation test. FTIR analysis for rPLA20GS composite showed the presence of additional peaks representing $\mathrm{O}-\mathrm{P}-\mathrm{O}$ bending vibrations after 14 days of incubation (Fig. 5) which are characteristics for $\mathrm{PO}_{4}$ groups in phosphates and hydroxyapatites [29-32]. However, further analysis of chemical composition of the scaffolds surface (Table 1) exhibited significantly lower $\mathrm{Ca} / \mathrm{P}$ ratio than for hydroxyapatite (1.67). Ca/P ratio from the range of $0.5-1.0$ suggests the occurrence of other calcium phosphates such as calcium metaphosphate $\mathrm{Ca}\left(\mathrm{PO}_{3}\right)_{2}(\mathrm{Ca} / \mathrm{P}=0.5)$, heptacalcium phosphate $\mathrm{Ca}_{7}\left(\mathrm{P}_{5} \mathrm{O}_{16}\right)_{2}(0.7)$, calcium phosphate $\mathrm{Ca}_{2} \mathrm{P}_{2} \mathrm{O}_{7}$ (1.0) or dicalcium phosphate $\mathrm{CaHPO}_{4}$ [34].

Due to the relatively high reactivity of the added particles, traversal cracks in the fibers can occur together with separation in the interconnection area of polymer matrix and glass-ceramic particles [4]. Those places with interrupted continuity promote release of degradation products to the incubation solution which, on the one hand, enhance the degradation process, but, on the other hand, influence the $\mathrm{pH}$ value. The most suitable range of $\mathrm{pH}$ values for proteins and other biological molecules in most of the body fluids is from 7.35 to 7.45 [35]. Significant deviations in $\mathrm{pH}$ values upon degradation of the scaffold can cause inflammatory reactions and pose a threat to tissue recovery. Therefore, it is of great importance to maintain the $\mathrm{pH}$ of surrounding tissue medium in preferable range [36, 37]. As shown in Fig. 6, the investigated PLA-CaP ormoglass composites undergo a hydrolytic degradation during incubation in SBF. The degradation process of PLA induces production of carboxylic acid which may significantly decrease the $\mathrm{pH}$. Table 2 presents the $\mathrm{pH}$ values after 21 days of incubation of PLA-CaP ormoglass composites in SBF solution. It is clear that the incorporation of the $\mathrm{CaP}$ ormoglass nanoparticles into the PLA matrix impedes the decrease in medium $\mathrm{pH}$ and allows to sustain it in the right range. The addition of 20 and $30 \mathrm{wt} \%$ of $\mathrm{CaP}$ ormoglass helps to maintain the $\mathrm{pH}$ in the range of 7.35-7.45 after 3 weeks of incubation in SBF.

Finally, the protein adsorption test was done to assay whether electrospun PLA-CaP ormoglass composites can support protein anchorage to the surface and therefore improve the efficiency of binding the scaffold with the tissue. It is a crucial matter to investigate the protein 
Table 2 The $\mathrm{pH}$ values of incubation medium after 21 days for PLA-CaP ormoglass composites

\begin{tabular}{ll}
\hline Material & $\mathrm{pH}$ value \\
\hline aPLA & $7.33 \pm 0.04$ \\
aPLA10GS & $7.34 \pm 0.04$ \\
aPLA20GS & $7.38 \pm 0.03$ \\
aPLA30GS & $7.38 \pm 0.04$ \\
rPLA & $7.33 \pm 0.04$ \\
rPLA10GS & $7.35 \pm 0.03$ \\
rPLA20GS & $7.37 \pm 0.04$ \\
rPLA30GS & $7.41 \pm 0.03$ \\
\hline
\end{tabular}

adsorption on the biomaterial surface as it is the first stage of interaction between material and body fluids and it influences the proper cell adhesion [17, 38, 39]. FTIR results (Fig. 7) indicate that despite low concentration of protein solution, BSA adsorbed to PLA-CaP ormoglass composites (both aligned and randomly oriented) with 20 and $30 \mathrm{wt} \%$ of ormoglass nanoparticles which was not observed for pure PLA scaffolds. It was manifested by the presence of two additional peaks at $\sim 1655$ and $\sim 1540 \mathrm{~cm}^{-1}$ for these composites which corresponds to $\mathrm{C}=\mathrm{O}$ as well as $\mathrm{C}-\mathrm{N}$ groups in amides $\mathrm{I}$ and $\mathrm{N}-\mathrm{H}$ bending in amide II, respectively [33].

BSA is well known for its good calcium-binding properties [40], and the ormoglass nanoparticles consist of a significant amount of calcium (30 wt $\%$ ). Therefore, better molecule adsorption on the materials with higher ormoglass concentration results from higher $\mathrm{Ca}$ concentration and more numerous binding sites available for proteins. Besides, it has been reported that both BSA and PLA fibers exhibit electronegative potential. The addition of ormoglass may increase the affinity of the protein to the composite fibers by changing its surface charges [17].

The promising results of degradation test in SBF and protein adsorption on the surface of the investigated PLA-CaP ormoglass composites suggest these hybrid fibrous scaffolds have a great potential for clinical use in bone tissue engineering. Our strategy toward development of the smart biomaterials platform for guided bone regeneration is based on a simple and cost-efficient fabrication method which is realistic to a clinical perspective, and materials able to promote angiogenesis and enhance vascularization in vivo.

\section{Conclusions}

Hybrid PLA-CaP ormoglass composites with different ormoglass nanoparticles contents $(0,10,20$ and $30 \mathrm{wt} \%)$ and fibers orientation (aligned and random) were successfully fabricated via electrospinning. Complex morphological and physicochemical analysis of PLA-CaP ormoglass composites before and after in vitro degradation test in SBF solution confirmed their biological potential which can be summarized as follows:

1. The presence of ormoglass nanoparticles in PLA/CaP ormoglass composites may promote bone regeneration by enhancing degradation process by $\mathrm{Ca}$ release and formation of CaP-based precipitations. The degradation process of PLA/CaP ormoglass nonwovens was accompanied by precipitation of numerous $\mathrm{CaP}$ compounds with extended topography and cauliflower-like shape, whereas no CaP compounds formed in case of pure PLA nonwovens (both aligned and randomly oriented).

2. Random fiber orientation seems to be preferable for $\mathrm{CaP}$ compounds deposition upon in vitro degradation. $\mathrm{CaP}$ compounds precipitated firstly for randomly oriented composite nonwovens with 20 and $30 \mathrm{wt} \%$ addition of ormoglass after 7 days of incubation in SBF, whereas for their aligned counterparts only small amounts of $\mathrm{CaP}$ precipitates were observed after 21 days of incubation.

3. The investigated PLA-CaP ormoglass composites underwent a hydrolytic degradation during incubation in $\mathrm{SBF}$, which results in carboxylic acid production and decrease in $\mathrm{pH}$ value. However, the incorporation of the $\mathrm{CaP}$ ormoglass nanoparticles into the PLA matrix impedes the decrease in medium $\mathrm{pH}$ and allows to sustain it in the right range of 7.35-7.45 after 3 weeks of incubation in SBF.

4. Moreover, the protein adsorption test exhibited that the presence of ormoglass nanoparticles increases the bioactivity of PLA-CaP ormoglass composites. The bovine serum albumin (used as a model protein) adsorbed to composite nonwovens (both aligned and randomly oriented) with 20 and $30 \mathrm{wt} \%$ of ormoglass which was not observed for pure PLA scaffolds.

Acknowledgements This work was supported by funding from the European Commission within the project NANGIOFRAC (project no. PI11/03030).

\section{Compliance with ethical standards}

Conflict of interest The authors declare that they have no conflict of interest.

Ethical approval The authors state that the research was conducted according to ethical standards.

Open Access This article is licensed under a Creative Commons Attribution 4.0 International License, which permits use, sharing, adaptation, distribution and reproduction in any medium or format, as long as you give appropriate credit to the original author(s) and the source, provide a link to the Creative Commons licence, and indicate if changes were made. The images or other third party material in this article are 
included in the article's Creative Commons licence, unless indicated otherwise in a credit line to the material. If material is not included in the article's Creative Commons licence and your intended use is not permitted by statutory regulation or exceeds the permitted use, you will need to obtain permission directly from the copyright holder. To view a copy of this licence, visit http://creativecommons.org/licenses/by/4.0/.

\section{References}

1. Holzwarth JM, Ma PX. Biomimetic nano fibrous scaffolds for bone tissue engineering. Biomaterials. 2011;32:9622-9.

2. Rajzer I, Menaszek E, Kwiatkowski R, Planell JA, Castano O. Electrospun gelatin/poly( $\varepsilon$-caprolactone) fibrous scaffold modified with calcium phosphate for bone tissue engineering. Mater Sci Eng C. 2014;44:183-90.

3. Rajzer I, Menaszek E, Castano O. Electrospun polymer scaffolds modified with drugs for tissue engineering. Mater Sci Eng C. 2017;77:493-9.

4. Navarro M, Ginebra MP, Barbosa MA. In vitro degradation behavior of a novel bioresorbable composite material based on PLA and a soluble CaP glass. Acta Biomater. 2005;1:411-9.

5. Navarro M, Ginebra MP, Planell JA, Zeppetelli S, Ambrosio L. Development and cell response of a new biodegradable composite scaffold for guided bone regeneration. J Mater Sci Mater Med. 2004;15:419-22.

6. Charles-Harris M, Koch MA, Melba N, Lacroix D, Engel E, Planell JA. A PLA/calcium phosphate degradable composite material for bone tissue engineering : an in vitro study. J Mater Sci Mater Med. 2008;19:1503-13.

7. Nampoothiri KM, Nair NR, John RP. An overview of the recent developments in polylactide (PLA) research. Bioresour Technol. 2010;101:8493-501.

8. Xiao L, Wang B, Yang G, Gauthier M. Poly (lactic acid)-based biomaterials: synthesis, modification and applications. Biomed Sci Eng Technol. 2012;20:247-82.

9. Fraisl P, Mazzone M, Schmidt T, Carmeliet P. Regulation of angiogenesis by oxygen and metabolism. Dev Cell. 2009;16:167-79.

10. Arkudas A, Balzer A, Buehrer G, Arnold I, Hoppe A, Detsch R, Newby P, Fey T, Greil P, Horch RE, Boccaccini AR, Kneser U. Evaluation of angiogenesis of bioactive glass in the arteriovenous loop model. Tissue Eng. 2013;19:479-86.

11. Gritsch L, Conoscenti G, La V, Nooeaid P, Boccaccini AR. Polylactide-based materials science strategies to improve tissue-material interface without the use of growth factors or other biological molecules. Mater Sci Eng C. 2019;94:1083-101.

12. Mao D, Li Q, Li D, Chen Y, Chen X, Xu X. Fabrication of 3D porous poly(lactic acid)-based composite scaffolds with tunable biodegradation for bone tissue engineering. Materials. 2018;142:1-10.

13. Ciraldo FE, Conoscenti G, Carfi F. In vitro degradation and bioactivity of composite poly-L-lactic (PLLA)/bioactive glass (BG) scaffolds: comparison of 45S5 and 1393BG compositions. J Life Mater Sci. 1393BG;53:2362-74.

14. Serio F, Miola M, Vern E, Pisignano D, Boccaccini AR. Electrospun filaments embedding bioactive glass particles with ion release and enhanced mineralization. Nanomaterials. 2019;182:1-15.

15. Bellucci D, Braccini S, Chiellini F, Balasubramanian P, Boccaccini AR, Cannillo V. Bioactive glasses and glass-ceramics versus hydroxyapatite : comparison of angiogenic potential and biological responsiveness. J Biomed Mater Res. 2019;107:2601-9.
16. Navarro M, Ginebra M, Cle J, Martı S. Physicochemical degradation of titania-stabilized soluble phosphate glasses for medical applications. J Am Ceram Soc. 2003;86:1345-52.

17. Sachot N, Castaño O, Oliveira H, Martí-Muñoz J, Roguska A, Amedee J, et al. A novel hybrid nanofibrous strategy to target progenitor cells for cost-effective in situ angiogenesis. J Mater Chem B. 2016;4:6967-78.

18. Oliveira H, Catros S, Castano O, Rey S, Siadous R, Clift D, et al. The proangiogenic potential of a novel calcium releasing composite biomaterial: orthotopic in vivo evaluation. Acta Biomater. 2017;54:377-85.

19. Aguirre A, González A, Planell JA, Engel E. Extracellular calcium modulates in vitro bone marrow-derived Flk-1 + CD34 + progenitor cell chemotaxis and differentiation through a calcium-sensing receptor. Biochem Biophys Res Commun. 2010;393:156-61.

20. Sanzana ES, Navarro M, Macule F, Suso S, Planell JA, Ginebra MP. Of the in vivo behavior of calcium phosphate cements and glasses as bone substitutes. Acta Biomater. 2008;4:1924-33.

21. Navarro-Requena C, Perez-Amodio S, Castano O, Engel E. Wound healing-promoting effects stimulated by extracellular calcium and calcium-releasing nanoparticles on dermal fibroblasts. Nanotechnology. 2018;29:395102.

22. Oliveira H, Catros S, Boiziau C, Siadous R, Marti-munoz J, Bareille R, et al. The proangiogenic potential of a novel calcium releasing biomaterial: impact on cell recruitment. Acta Biomater. 2016;29:435-45.

23. Kokubo T, Takadama $\mathrm{H}$. How useful is $\mathrm{SBF}$ in predicting in vivo bone bioactivity? Biomaterials. 2006;27:2907-15.

24. Williams DH, Fleming I. Spectroscopic methods in organic chemistry. 2nd ed. Maidenhead: McGraw-Hill Book Company Limited; 1973.

25. Lucacel RC, Maier M, Simon V. Structural and in vitro characterization of $\mathrm{TiO}_{2}-\mathrm{CaO}-\mathrm{P}_{2} \mathrm{O}_{5}$ bioglasses. J Non Cryst Solids. 2010;356:2869-74.

26. ElBatal HA, Khalil EMA, Hamdy YM. In vitro behavior of bioactive phosphate glass-ceramics from the system $\mathrm{P}_{2} \mathrm{O}_{5}-\mathrm{Na}_{2} \mathrm{O}-\mathrm{CaO}$ containing titania. Ceram Int. 2009;35:1195-204.

27. Aguiar H, Serra J, González P, León B. Structural study of solgel silicate glasses by IR and Raman spectroscopies. J Non Cryst Solids. 2009;355:475-80.

28. Sachot N, Roguska A, Planell JA, Lewandowska M, Engel E, Castaño O. Fast-degrading PLA/ORMOGLASS fibrous composite scaffold leads to a calcium-rich angiogenic environment. Int J Nanomed. 2017;12:4901-19.

29. Gibson IR, Rehman I, Best SM, Bonfield W. Characterization of the transformation from calcium-deficient apatite to $\beta$-tricalcium phosphate. J Mater Sci Mater Med. 2000;11:799-804.

30. Liu DM, Yang Q, Troczynski T, Tseng WJ. Structural evolution of sol-gel-derived hydroxyapatite. Biomaterials. 2002;23:1679-87.

31. Stoch A, Jastrzębski W, Brozek A, Stoch J, Szaraniec J, Trybalska B, et al. FTIR absorption-reflection study of biomimetic growth of phosphates on titanium implants. J Mol Struct. 2000;555:375-82.

32. Rehman I, Bonfield W. Characterization of hydroxyapatite and carbonated apatite by photo acoustic FTIR spectroscopy. J Mater Sci Mater Med. 1997;8:1-4.

33. Twardowski J, Anzenbacher P. Raman and IR spectroscopy in biology and biochemistry. Chichester: Ellis Horwood Limited; 1994.

34. Vallet-Regí M. Ceramics for medical applications. J Chem Soc Dalt Trans. 2001;20:97-108.

35. Razaq S, Wilkins RJ, Urban JPG. The effect of extracellular $\mathrm{pH}$ on matrix turnover by cells of the bovine nucleus pulposus. Eur Spine J. 2003;12:341-9.

36. Maquet V, Boccaccini AR, Pravata L, Notingher I, Jérôme R. Porous poly $(\alpha$-hydroxyacid $) /$ Bioglass ${ }^{\circledR}$ composite scaffolds for 
bone tissue engineering. I: preparation and in vitro characterisation. Biomaterials. 2004;25:4185-94.

37. Blaker JJ, Day RM, Maquet V, Boccaccini AR. Novel bioresorbable poly(lactide-co-glycolide) (PLGA) and PLGA/bioglass composite tubular foam scaffolds for tissue engineering applications. Mater Sci Forum. 2004;455-456:415-9.

38. Anderson JM, Rodriguez A, Chang DT. Foreign body reaction to biomaterials. Semin Immunol. 2008;20:86-100.

39. Atthoff B, Hilborn J. Protein adsorption onto polyester surfaces: is there a need for surface activation? J Biomed Mater Res B. 2007;80B:121-30.
40. Fogh-Andersen N. Albumin/calcium association at different $\mathrm{pH}$, as determined by potentiometry. Clin Chem. 1977;23:2122-6.

Publisher's Note Springer Nature remains neutral with regard to jurisdictional claims in published maps and institutional affiliations. 